(C) 2005 IEEE. Reprinted, with permission, from J. Hu, H. L. Tsai and P. C. Wang, "Numerical Modeling of GMAW Arc", IEEE International Conference on Industrial Electronics, Technology \& Automation (IETA05), Bridgeport, Connecticut, 2005.

This material is posted here with permission of the IEEE. Such permission of the IEEE does not in any way imply IEEE endorsement of any of the University of Bridgeport's products or services. Internal or personal use of this material is permitted. However, permission to reprint/republish this material for advertising or promotional purposes or for creating new collective works for resale or redistribution must be obtained from the IEEE by writing to pubs-permissions@ieee.org. By choosing to view this document, you agree to all provisions of the copyright laws protecting it. 


\title{
NUMERICAL MODELING OF GMAW ARC
}

\author{
J. Hu*, H.L. Tsai and P.C. Wang \\ *Author for correspondence \\ Department of Mechanical Engineering, \\ University of Bridgeport, \\ Bridgeport, CT 06604, USA
}

\begin{abstract}
A comprehensive model has been developed to simulate the transient, coupled transport phenomena occurring during a gas metal arc welding process. This includes the arc plasma; melting of the electrode; droplet formation, detachment, transfer, and impingement onto the workpiece; and weld pool fluid flow and dynamics. The fluid flow and heat transfer in both the arc and the metal were simulated and coupled through the boundary conditions at the arc-metal interface at each time step. The detached droplet in the arc and the deformed weld pool surface were found to cause significant changes in the distributions of arc temperature and arc pressure, which are usually assumed to have Gaussian distributions at the workpiece surface. The comprehensive model could provide more realistic boundary conditions to calculate the heat transfer and fluid flow both in the plasma and the metal. The predicted arc plasma distribution, droplet flight trajectory, droplet acceleration and final weld bead shape compared favorably with the published experimental results. This paper was to present the heat transfer and fluid flow in the arc plasma.
\end{abstract}

\section{INTRODUCTION}

Gas metal arc welding (GMAW) is an arc welding process that uses a plasma arc between a continuous, consumable filler-metal electrode and the weld pool. GMA welding is one of the most important and popular welding technologies. Very complicated transport phenomena, including the arc plasma, electrode melting, and weld pool dynamics, occur during the GMA welding process. The trial-and-error procedures have been used in the industry to identify key welding parameters and to develop the GMA welding technologies. However, this weld-and-cut method, is not only very expensive and timeconsuming, but also cannot achieve the fundamental understanding on how the transport phenomena affects weld quality, such as weld penetration, weld bead shape, and the formation of porosity.

Many models have been developed to model the heat transfer and fluid flow in the arc plasma for both GTAW [118] and GMAW [19-24]. Mckelliget and Szekely [1], Choo et al. [2] and Goodarzi et al. [3] have simulated the arc column by assuming the current density distribution at the cathode surface in GTAW. Fan et al. [4-5] used fixed temperature boundary condition at the cathode tip to calculate the arc column in GTAW. Zhu et al. [6] developed a unified model to simulate the arc column, the cathode and the cathode sheath in GTAW. Lowke et al. [7-8] simplified the unified model to treat the electrode in a special way at the cathode surface to account for electrode effects [7] or neglect the electrode sheath [8]. The simplified models [7-8] reduced the computation time to $1 \%$ of the original unified model and gave fair results in agreement with experimental results when 0.005-0.01 cm mesh size was chosen around the cathode tip. These simplified models have been used and further developed by many researchers [9-18] to calculate the heat transfer and fluid flow in the arc column.

Both GTAW and GMAW have a plasma arc struck between an electrode and a workpiece. Even though the GTAW has an inert tungsten cathode as the electrode and the electrode of GMAW is a melting metal and usually set as the anode, the GTAW arc model can be adopted to model the GMAW arc. Jonsson [19] adopted the GTAW arc model of Mckelliget and Szekely [1] to calculate the arc column by assuming a current density distribution at the cathode spot. Zhu et al. [20] calculated the anode temperature profile by incorporating the simplified arc model of Lowke et al. [8] into a one-dimensional conduction model of the moving electrode in GMAW. The heat input to the electrode was estimated from the arc plasma, and the 'molten' metal was discarded when its temperature reached the melting point. Haidar and Lowke [21] and Haidar [22] extended the simplified arc model of Lowke et al. [8] to simulate the droplet formation in GMAW. They were the first to simulate the dynamic interaction of the arc plasma and the droplet. Haidar [13, 23, 24] further developed this GMAW model to take into account the sheath effect at the anode surface. However, the droplet was eliminated immediately when it was detached from the electrode tip. The weld pool dynamics was also neglected and the workpiece was treated as a flat plate. The fluid flow in the weld pool was not calculated and only conduction was considered. Zhu et al. [25] have developed a comprehensive model to simulate the arc column, droplet formation, detachment, transfer and impingement onto the workpiece and the weld pool dynamics. However, the simulated arc plasma poorly matched the experimental [26-30] results and the simulation results from aforementioned arc models [1-24].

Many mathematical models [31-43] have been proposed to simulate the transport phenomena during the GMA welding process without considering the arc plasma. They were limited to a portion of the welding process, for example, weld pool dynamics, and/or involved many simplifications, such as a Gaussian distribution of the arc pressure.

In this paper, a comprehensive model has been developed to simulate the transient, coupled transport phenomena 
occurring during a gas metal arc welding process. This includes the arc plasma; melting of the electrode; droplet formation, detachment, transfer, and impingement onto the workpiece; and weld pool fluid flow and dynamics.

\section{MATHEMATICAL MODLELS}

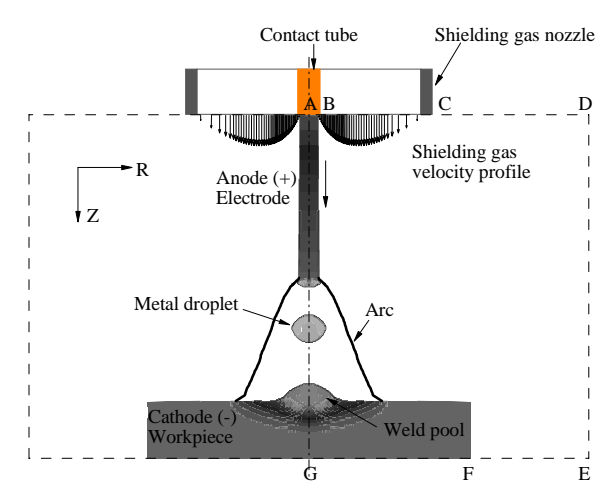

Fig. 1. A schematic representation of a GMAW system including the electrode, the arc, and the weld pool (not to scale).

Fig. 1 is a schematic representation of a two-dimensional axisymmetric GMAW system, with the computational domain marked by ABCDEFGA. There are three phases inside the computational domain: a solid phase, a liquid phase and a gas phase. The solid phase includes the unmelted electrode and part of the workpiece, while the liquid phase includes the melted electrode, falling droplet, and part of the workpiece. The gas phase includes the partially ionized arc plasma and shielding gas. Between the liquid zone and solid zone, there is a small zone called mushy zone where the solid and liquid metal coexist. A continuum formulation [44] was used to handle the metal domain consisting of the solid phase, liquid phase and mushy zone. Latent heat during melting and solidification was considered using the enthalpy method. As the properties of gas are far different from those of metal, two computational domains are used for computational robust and efficiency. One computational domain is used to calculate the heat transfer and fluid flow in the gas phase and another is used for metal, which includes both solid phase and liquid phase. The heat transfer and fluid flow in both computational domains are coupled with the electromagnetic field in both domains.

The differential equations governing the conservation of mass, momentum, and energy based on the continuum formulation given by Diao and Tsai [44] are employed in the present study, and the current continuity equation is used to calculate the current density distribution. The equations are given below:

Mass continuity

$\nabla \cdot(\rho \boldsymbol{V})=0$

Momentum

$$
\begin{aligned}
& \frac{\partial}{\partial t}(\rho u)+\nabla \cdot(\rho \boldsymbol{V} u)=\nabla \cdot\left(\mu_{l} \frac{\rho}{\rho_{l}} \nabla u\right)-\frac{\partial p}{\partial r}-\frac{\mu_{l}}{K} \frac{\rho}{\rho_{l}}\left(u-u_{s}\right) \\
& -\frac{C \rho^{2}}{K^{1 / 2} \rho_{l}}\left|u-u_{s}\right|\left(u-u_{s}\right)-\nabla \cdot\left(\rho f_{s} f_{l} \boldsymbol{V}_{r} u_{r}\right)-J_{z} \times B_{\theta} \\
& \frac{\partial}{\partial t}(\rho v)+\nabla \cdot(\rho \boldsymbol{V} v)=\nabla \cdot\left(\mu_{l} \frac{\rho}{\rho_{l}} \nabla v\right)-\frac{\partial p}{\partial z}-\frac{\mu_{l}}{K} \frac{\rho}{\rho_{l}}\left(v-v_{s}\right) \\
& -\frac{C \rho^{2}}{K^{1 / 2} \rho_{l}}\left|v-v_{s}\right|\left(v-v_{s}\right)-\nabla \cdot\left(\rho f_{s} f_{l} V_{r} v_{r}\right)+\rho g \beta_{T}\left(T-T_{0}\right)+J_{r} \times B_{\theta}
\end{aligned}
$$

Energy

$$
\begin{aligned}
& \frac{\partial}{\partial t}(\rho h)+\nabla \cdot(\rho \boldsymbol{V} h)=\nabla \cdot\left(\frac{k}{c_{s}} \nabla h\right)+\nabla \cdot\left(\frac{k}{c_{s}} \nabla\left(h_{s}-h\right)\right)-\nabla \cdot \\
& \left(\rho\left(\boldsymbol{V}-\boldsymbol{V}_{s}\right)\left(h_{l}-h\right)\right)-\Delta H \frac{\partial f_{l}}{\partial t}+\frac{J_{r}^{2}+J_{z}^{2}}{\sigma_{e}}-S_{R}+\frac{5 k_{b}}{e}\left(\frac{j_{r}}{c_{s}} \frac{\partial h}{\partial r}+\frac{j_{z}}{c_{s}} \frac{\partial h}{\partial z}\right)
\end{aligned}
$$

Current continuity

$$
\nabla^{2} \phi=\frac{1}{r} \frac{\partial}{\partial r}\left(r \frac{\partial \phi}{\partial r}\right)+\frac{\partial^{2} \phi}{\partial z^{2}}=0
$$

Ohm's law

$$
J_{r}=-\sigma_{e} \frac{\partial \phi}{\partial r}, J_{z}=-\sigma_{e} \frac{\partial \phi}{\partial z}
$$

Maxwell's equation

$$
B_{\theta}=\frac{\mu_{0}}{r} \int_{0}^{r} J_{z} r d r
$$

In Eqs. (1)-(4), $u$ and $v$ are the velocities in the $r$ and $z$ directions, respectively. $V_{r}\left(=V_{l}-V_{s}\right)$ is the relative velocity vector between the liquid phase and the solid phase in the mushy zone. The subscripts $s$ and $l$ refer to the solid and liquid phases, respectively, and the subscript 0 represents the initial condition. $\quad p$ is the pressure; $T$ is the temperature; $h$ is the enthalpy; $\phi$ is the electrical potential; $\rho$ is the density; $\mu$ is the viscosity; $k$ is the thermal conductivity; $g$ is the gravitational acceleration; $\beta_{T}$ is the thermal expansion coefficient; $c$ is the specific heat; $\sigma_{e}$ is the electrical conductivity; $J_{r}$ and $J_{z}$ are current densities, in the respective $r$ and $z$ directions; $B_{\theta}$ is the self-induced electromagnetic field; $S_{R}$ is the radiation heat loss; $\mu_{0}$ is the magnetic permeability; $k_{b}$ is the Stefan-Boltzmann constant; and $e$ is the electronic charge.

The third and fourth terms on the right-hand side of Eqs. (2) and (3) represent the respective first- and second-order drag forces for the flow in the mushy zone. The fifth term on the right-hand side of Eqs. (2) and (3) represents an interaction between the solid and the liquid phases. The second term on the right-hand side of Eq. (4) represents the net Fourier diffusion flux. While the third term represents the energy flux associated with the relative phase motion, and the forth term is used to consider the latent heat of fusion. All the terms mentioned in this paragraph are zero, except in the mushy zone. When Eqs. (2)-(4) are used to calculate the arc plasma, these terms associated with the mushy zone are set to zero and all the thermal physical properties are replaced by those of the arc plasma. 
The second-to-last term on the right-hand side of Eq. (3) is the thermal expansion term. The last term of Eq. (2) and Eq. (3) is the electromagnetic force term. The last three terms in Eq. (4) are Ohmic heating, radiation loss, and electron enthalpy flow, respectively.

Only half of the entire physical domain is calculated due to the cylindrical symmetry along the centerline AG. The wire feed rate is incorporated through a boundary condition on axial velocity along $\mathrm{AB}$. The imposed shielding gas flow is set through a boundary condition on axial velocity along BC. A constant mass flow boundary condition is used for the open boundaries CD and DE. The temperature boundaries along $\mathrm{AD}, \mathrm{DE}$, and EG are determined by the ambient condition, which is set as room temperature. Uniform current density is specified along AB. The voltage is set to zero at the bottom of the workpiece FG.

Two computational domains are used to calculate arc plasma and metal. For the arc plasma domain, the metal domain was treated as inner obstacles, while the plasma temperature, velocity, and pressure distributions were calculated. For the metal domain, a volume-of-fluid (VOF) method [45] was used to handle the free surfaces for the droplet and the surface of the weld pool. Additional body force source terms are added to the momentum transport equations at the metal free surface to consider the effects of surface tension, Marangoni shear stress, arc plasma shear stress and arc pressure. Additional source terms [46] are added to the energy equation for the special treatment of heat transfer near the anode sheath and the cathode sheath.

The current distribution is greatly influenced by the temperature in the arc column and the shape of the metal domain, but it is only slightly influenced by the temperature distribution in the metal domain as the electrical conductivity of metal varies slightly with temperature. Therefore, the current continuity equation and its associated boundary conditions are solved in the entire domain, while other primary variables, including $p, u, v$, and $T$, are calculated separately in the metal domain and the arc domain. The current continuity equation is iterated with the transport equations in the arc domain to obtain the current density distribution for both the arc domain and the metal domain. Iterations are required to assure convergence of each domain and then the boundary conditions are calculated from each domain for the coupling between the two domains.

For the metal domain, the method developed by Torrey et al. [45] was used to solve $p, u, v$ and $T$. This method is Eulerian and allows for an arbitrary number of segments of free surface with any reasonable shape. The basic procedure for advancing the solution through one time step, $\delta t$, consists of three steps. First, at the beginning of the time step, explicit approximations to the momentum equations (2) and (3) are used to find provisional values of the new time velocities. Second, an iterative procedure is used to solve for the advanced time pressure and velocity fields that satisfy Eq. (1) to within a convergence criterion at the new time. Third, the energy equation is solved.
For the arc plasma domain, a fully implicit formulation is used for the time-dependent terms, and the combined convection/diffusion coefficients are evaluated using an upwind scheme. The SIMPLE algorithm [47] is applied to solve the momentum and continuity equations to obtain the velocity field. At each time step, the current continuity equation is solved first, based on the updated parameters. Current density and electromagnetic force are then calculated for the momentum and energy equations. The momentum equations and the continuity equation are then solved in the iteration process to obtain pressure and velocity. The energy equation is solved to get the new temperature distribution. Next, the temperature-dependent parameters are updated, and the program goes back to the first step to calculate the current continuity equation. This process is repeated for each time step until the convergence criteria are satisfied.

\section{RESULTS AND DISCUSSION}

The electrode is mild steel with a $0.16 \mathrm{~cm}$ diameter. The workpiece is also a mild steel disk with a $3 \mathrm{~cm}$ diameter and a $0.5 \mathrm{~cm}$ thickness. The current is set to be constant at $220 \mathrm{~A}$ and the welding time is $1 \mathrm{~s}$. The imposed argon shielding gas flows out of a gas nozzle with a $1.91 \mathrm{~cm}$ inner diameter at a rate of $24 \mathrm{l} / \mathrm{min}$. The contact tube is set flush with the bottom of the gas nozzle and is $2.54 \mathrm{~cm}$ above the workpiece. The initial arc length is set as $0.8 \mathrm{~cm}$. The wire feed rate is 4.5 $\mathrm{cm} / \mathrm{s}$.

In this section, the arc characteristics during a welding process are presented. In order to increase the readability of flow direction, only a quarter of the grid nodes were used in Fig. 2 and 3. The shape of the electrode and workpiece are marked with thick lines.

Fig. 2 (a)-(d) shows the distributions of temperature, pressure, plasma velocity, and current at different instants, from $t=100 \mathrm{~ms}$ to $\mathrm{t}=400 \mathrm{~ms}$. From the temperature contours in the plasma at $\mathrm{t}=100 \mathrm{~ms}$ in Fig. 2 (a), it can be seen that the arc has a bell-shaped envelope, which covers the droplet and expands as it approaches the workpiece. The maximum temperature of the plasma is found to be $19300 \mathrm{~K}$ on the axis near the bottom of the droplet. The corresponding velocity distribution at $\mathrm{t}=100 \mathrm{~ms}$ in Fig. 2 (c) shows a strong downward arc plasma flow underneath the droplet. The maximum axial velocity in the arc column is found to be 230 $\mathrm{m} / \mathrm{s}$ on the axis. The corresponding arc pressure contours at $\mathrm{t}=$ 100 ms are shown in Fig. 2 (b), which shows two high pressure regions. One is underneath the droplet with a maximum of $800 \mathrm{~Pa}$ above the ambient pressure, and the other is near the cathode with a maximum of $600 \mathrm{~Pa}$ above the ambient pressure. The high temperature arc column and high speed arc plasma jet are formed by the high current flow in the arc column, which is drawn in Fig. 2 (d). The high current flow in the arc column provides heat to keep the arc column hot, and in turn, the high temperature arc column maintains a highly conductive path for the current to flow through. From Fig. 2 (d), it can be seen that current tends to diverge in the arc column after it flows out of electrode tip. The divergence in 
current generates an inward and downward force underneath the electrode tip, which has a pinch effect on arc plasma. The pinch effect of the electromagnetic force in the arc column, which is shown in Fig. 3, draws the arc plasma and the surrounding shielding gas to flow inward at the electrode tip and then downward along the axial direction to the workpiece.

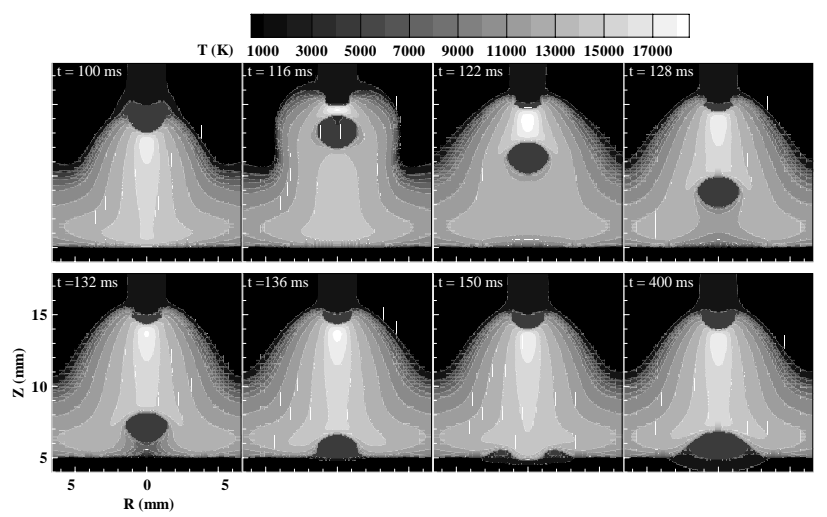

(a) Temperature
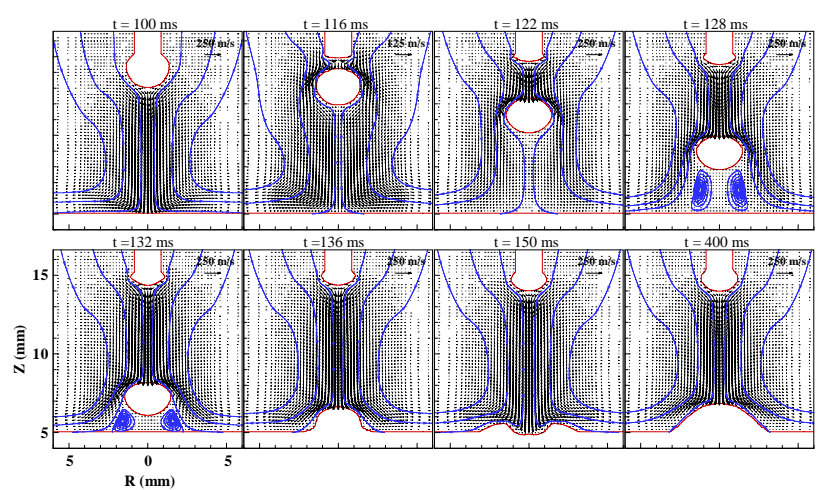

(c) Velocity
The inward arc plasma flow forms a high arc pressure zone underneath the electrode tip. When the downward arc plasma flow reaches the wrokpiece at the bottom, the downward momentum was retarded and a high pressure zone forms at the workpiece.

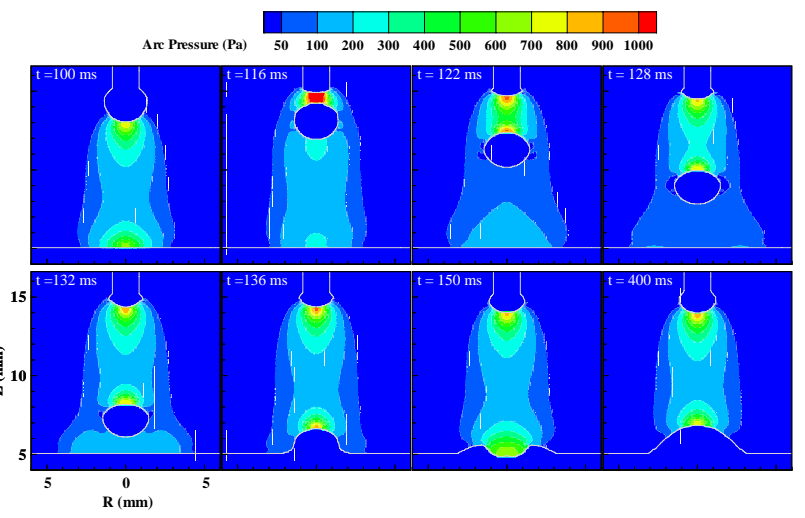

(b) Pressure
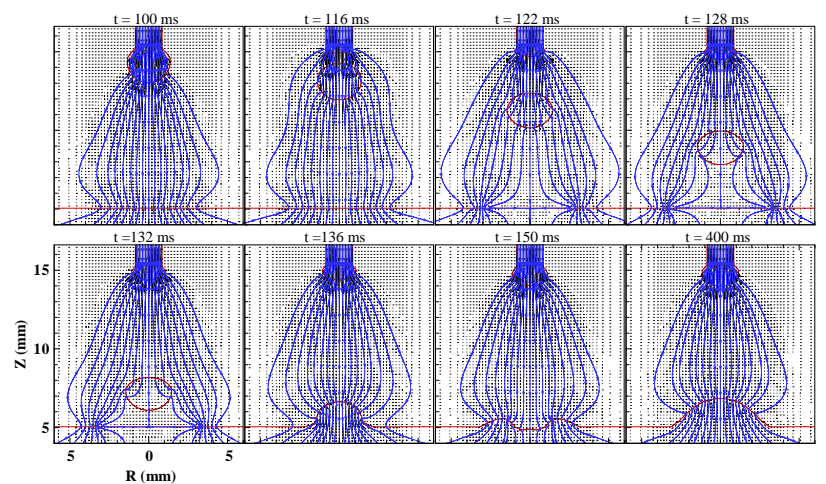

(d) Current

Fig. 2. Distributions of temperature, pressure, velocity and current in the arc plasma.

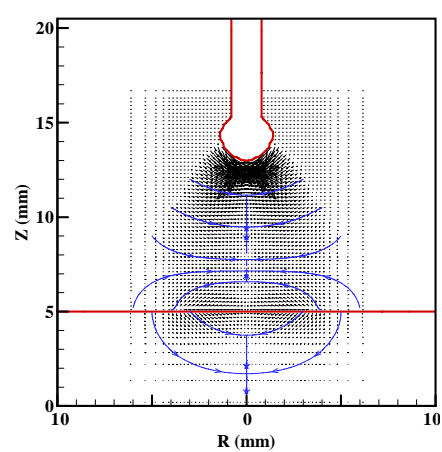

Fig. 3. Electromagnetic force at $\mathrm{t}=100 \mathrm{~ms}$.

After the droplet is detached from the electrode, new arc plasma is struck between the electrode tip and the top surface of the detached droplet. During the process of the detached droplet being transferred to the workpiece, the existence of the moving droplet greatly distorts the arc shape. From the temperature contour and velocity distribution from $t=116 \mathrm{~ms}$ to $\mathrm{t}=132 \mathrm{~ms}$ in Fig. 2 (a) and (c), it can be seen that arc plasma flows around the moving droplet. The high temperature and high velocity arc column is limited to the region between the electrode tip and the top of the detached droplet. The arc plasma temperature underneath the moving droplet decreases continuously after the droplet is detached from the electrode. The high velocity plasma flow induced by the pinch effect of the electromagnetic force underneath the moving droplet subsides and vortices form underneath the droplet when it moves down to the workpiece. These phenomena are supported by the experimental results of Jones et al. [27-30], which has observed that arc plasma tended to flow around the detached droplet.

From the current distribution in Fig. 2 (d), it can be seen that current also flows around the detached droplet. Only a small amount of current flows through the detached droplet, except at $\mathrm{t}=116 \mathrm{~ms}$, when the droplet has just been detached and the temperature underneath the droplet is still relatively 
high. When the detached droplet moves farther away from the electrode tip in the cases of $t=122 \mathrm{~ms}$ to $132 \mathrm{~ms}$, more current flows around the detached droplet. The arc plasma temperature quickly decreases when current flow decreases underneath the detached droplet due to the high radiation loss and low capacity of the plasma. The lower plasma temperature underneath the detached droplet further reduces the current flow in the plasma beneath the droplet, and hence the plasma temperature continues to drop. At the surface of the workpiece, the current bypassed around the detached droplet tends to converge at a place other than the spot directly underneath the droplet.

As it is shown in Fig. 2 (b), the existence of the detached droplet also dramatically changes the arc pressure distribution underneath the droplet. The high arc pressure, which was under the droplet before it was detached, decreases rapidly. The pressure difference between the upper and lower surfaces of the droplet helps to push the detached droplet down to the workpiece.

The current distribution in the weld pool is greatly influenced by the shape of the weld pool surface. The temperature, arc plasma velocity, current and arc pressure distributions from $\mathrm{t}=136 \mathrm{~ms}$ to $\mathrm{t}=400 \mathrm{~ms}$ in Fig. 2 show the influence of the weld pool shape on the arc plasma. The current tends to converge on the projected area at the workpiece, which may be at the workpiece center as in the cases of both $t=136 \mathrm{~ms}$ and $\mathrm{t}=400 \mathrm{~ms}$ or not at the center as that of $\mathrm{t}=150 \mathrm{~ms}$. The temperature distribution and the arc pressure distribution at the deformed weld pool surface from $t=$ $136 \mathrm{~ms}$ to $\mathrm{t}=400 \mathrm{~ms}$ in Fig. 2, also show a different pattern from those at the flat weld pool surface.

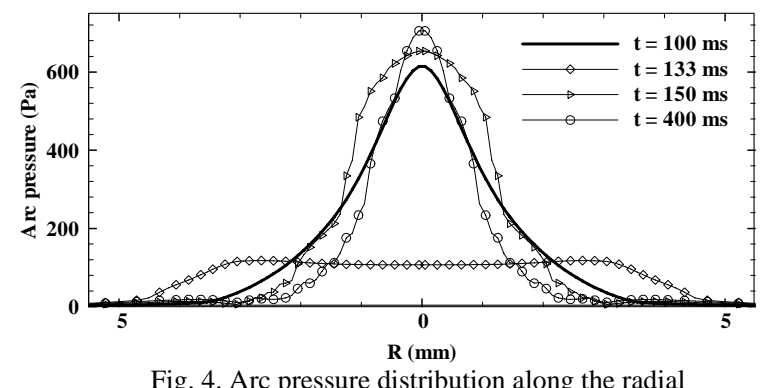

Fig. 4. Arc pressure distribution along the radial direction at the workpiece surface.

In the previous models of simulating the weld pool dynamics, the arc pressure distribution at the center of the workpiece surface was assumed as a Gaussian distribution with a fixed amplitude and distribution radius. However, the arc pressure distribution at the workpiece surface changes dramatically during the welding process, as shown in Fig. 4. Thus, it shows that the assumed Gaussian distribution of the arc pressure cannot reflect the real arc pressure distribution at the weld pool surface. Similarly, the current distribution and heat flux cannot be assumed as Gaussian distributions with fixed amplitude and fixed distribution radius. Thus, a comprehensive model that simulates the coupling of the arc and metal domain is needed to provide better boundary conditions at the metal surface for both domains.

\section{CONCLUSION}

A comprehensive model has been used to simulate the transport phenomena occurring during a gas metal arc welding process. An interactive coupling between the arc plasma; the melting of the electrode; the droplet generation, detachment, transfer, and impingement onto the workpiece; and weld pool dynamics were considered. The heat transfer and fluid flow in the arc column were studied based on the transient distributions of current, temperature, velocity, and pressure in the arc plasma, droplet, and weld pool calculated in the comprehensive model. The moving droplet stuck between the electrode tip and the workpiece and the deformed weld pool were found to distort the arc flow and affect the current, temperature, velocity, and pressure distribution in the arc column. The assumed Gaussian distributions of the arc pressure, current and heat flux at the weld pool surface in the traditional models were shown not to be representative of the real distributions in the welding process. The coupled model can provide more realistic boundary conditions to the metal domain and thus can more accurately predict the heat transfer and fluid flow phenomena during the electrode melting, droplet generation, droplet transfer, weld pool dynamics and weld formation.

\section{REFERENCES}

[1] J. Mckelliget and J. Szekely, "Heat Transfer and Fluid Flow in the Welding Arc," Metall. Trans. 17A, 1986, pp. 1139-1148.

[2] R.T.C. Choo, J. Szekely and R.C. Westhoff, "On the calculation of the free surface temperature of gas-tungsten-arc weld pools from first principles: Part I. Modeling the welding arc," Metall. Trans. 23B, 1992, pp. 357-369.

[3] M. Goodarzi, R. Choo and J.M. Toguri, "The Effect of the Cathode Tip Angle on the GTAW Arc and Weld Pool: I. Mathematical Model of the Arc,” J. Phys. D: Appl. Phys. 30, 1997, pp. 27442756.

[4] H.G. Fan, S-J Na and Y.W. Shi, "Mathematical model of arc in pulsed current gas tungsten arc welding," J. Phys. D: Appl. Phys. 30, 1998, pp. 94-102.

[5] H.G. Fan, Y.W. Shi, "Numerical simulation of the arc pressure in gas tungsten arc welding," Journal of Material Processing Tech. 61, 1996, pp. 302-308.

[6] P. Zhu, J.J. Jowke, R. Morrow, "A Unified Theory of Free Burning Arcs, Cathode Sheaths and Cathodes,” J. Phys. D: Appl. Phys. 25, 1992, pp. 1221-1230.

[7] J.J. Lowke, R. Morrow and J. Haidar, "A Simplified Unified Theory of Arcs and Their Electrodes,” J. Phys. D: Appl. Phys. 30, 1997, pp. 2033-2042.

[8] J.J. Lowke, P. Kovitya and H.P. Schmidt, "Theory of Free-Burning Arc Columns Including the Influence of the Cathode," J. Phys. D: Appl. Phys. 25, 1992, pp. 1600-1606.

[9] P. Zhu, J.J. Jowke, R. Morrow and J. Haidar, "Prediction of Anode Temperatures of Free Burning Arcs,” J. Phys. D: Appl. Phys. 28, 1995, pp. 1369-1376.

[10] J. Haidar, "Departures from Local Thermodynamic Equilibrium in High-Current Free Burning Arcs in Argon,” J. Phys. D: Appl. Phys. 30, 1997, pp. 2737-2743.

[11] L. Sansonnens, J. Haidar, J.J. Lowke, "Prediction of Properties of Free Burning Arcs Including Effects of Ambipolar Diffusion,” J. Phys. D: Appl. Phys. 33, 2000, pp. 148-157.

[12] M. Tanaka, H. Terasaki, M. Ushio and J.J. Lowke, "A Unified Numerical Modeling of Stationary Tungsten-Inert Gas Welding Process,” Metall. Mater. Trans. 33A, 2002, pp. 2002-2043.

[13] J. Haidar, "A Theoretical Model for Gas Metal Arc Welding and Gas Tungsten Arc Welding. I.," J. Appl. Phys. 84 (7), 1998, pp. 3518-3529.

[14] R.J. Ducharme, P.D. Kapadia, J. Dowden I.M. Richardson, and M.F. Thornton, "A Mathematical Model of TIG Electric Arcs Operating in the Hyperbaric Range,” J. Phys. D: Appl. Phys. 29, 1996 pp. 2650-2658.

[15] J. Menart, J. Heberlein and E. Pfender, "Theoretical Radiative Transport Results for a FreeBurning Arc Using a Line-by-Line Technique,” J. Phys. D: Appl. Phys. 32, 1999, pp. 55-63.

[16] J. Menart, S. Malik and L. Lin, "Coupled Radiative, Flow and Temperature-Field Analysis of a Free-Burning Arc,” J. Phys. D: Appl. Phys. 33, 2000, pp. 257-269.

[17] H.P. Schmidt and G. Speckhofer, "Experimental and Theoretical Investigation of High-Pressure Arcs-Part I: the Cylindrical Arc Column (Two-Dimensional Modeling)," IEEE Trans. on Plasma Science, 24, 1996, pp. 1229-1238.

[18] G. Speckhofer and H.P. Schmidt, "Experimental and Theoretical Investigation of High-Pressure Arcs-Part II: the Magnetically Deflected Arc (Three-Dimensional Modeling), IEEE Trans. on Plasma Science, 24, 1996, pp. 1239-1248.

[19] P.G Jonsson, R.C.Westhoff, and J. Szekely, "Arc Characteristics in Gas-Metal Arc Welding of Aluminum Using Argon as the Shielding Gas,” J. Appl. Phys. 74, 1993, pp. 5997-6006.

[20] P. Zhu, M. Rados, and S.W. Simpson, "A Theoretical Study of Gas Metal Arc Welding System," Plasma Sources Sci. Technol. 4, 1995, pp. 495-500.

[21] J. Haidar, and J. Lowke, "Predictions of Metal Droplet Formation in Arc Welding," J. Appl. Phys. D: Appl. Phys. 29, 1996, pp. 2951-2960.

[22] J. Haidar, “An Analysis of the Formation of Metal Droplets in Arc Welding," J. Phys. D: Appl. Phys. 31, 1998, pp. 1233-1244 
[23] J. Haidar, "Prediction of Metal Droplet Formation in Gas Metal Arc Welding II,” J. Appl. Phys. 84 (7), 1998, pp. 3530-3540.

[24] J. Haidar, “An Analysis of Heat Transfer and Fume Production in Gas Metal Arc Welding. III.," J. Appl. Phys. 85 (7), 1998, pp. 3448-3459.

[25] F.L. Zhu, H.L. Tsai, S.P. Marin and P.C. Wang, "A Comprehensive Model on the Transport Phenomena during Gas Metal Arc Welding Process," Progress in Computational Fluid Dynamics, Vol. 4, No. 2, 2004, pp. 99-117.

[26] L. A. Jones, T.W. Eagar and J.H. Lang, "Images of Steel Electrode in $\mathrm{Ar}-2 \mathrm{OO}_{2}$ Shielding during Constant Current Gas Metal Arc Welding,” Welding Journal, Welding Research Supplement 1998, pp. 135-141s

[27] L.A. Jones, T.W. Eagar and J.H. Lang, "Magnetic Forces Acting on Molten Drops in Gas Metal Arc Welding,” J. Phys. D: Appl. Phys. 31, 1998, pp. 93-106.

[28] L.A. Jones, T.W. Eagar and J.H. Lang, "A Dynamic Model of Drops Detaching from a Gas Metal Arc Welding Electrode,” J. Phys. D: Appl. Phys. 31, 1998, pp. 107-123.

[29] H.G. Fan, and R. Kovacevic, "Droplet Formation, Detachment, and Impingement on the Molten Pool in Gas Metal Arc Welding," Metall. Trans. 30B, 1999, pp. 791-801.

[30] Fan, H.G. and Kovacevic, R., 1998, "Dynamic Analysis of Globular Metal Transfer in Gas Metal Arc Welding - a Comparison of Numerical and Experimental Results,” J. Phys. D: Appl. Phys. 31, pp. 2929-294

[31] S.K. Choi,, C.D. Yoo, and Y-S Kim, "The Dynamic Analysis of Metal Transfer in Pulsed Curren Gas Metal Arc Welding,” J. Phys. D: Appl. Phys. 31, 1998, pp. 207-215.

[32] S.K. Choi, C.D. Yoo, and Y-S Kim, "Dynamic Simulation of Metal Transfer in GMAW, Part 1: Globular and Spray Transfer Modes," Welding J., 1998, pp. 38-44s.

[33] G. Wang, P.G. Huang, and Y.M. Zhang, "Numerical Analysis of Metal Transfer in Gas Metal Arc Welding," Metall. Trans. 34B, 2003, pp. 345-353.

[34] F. Wang, W.K Hou, S.J. Hu, E. Kannatey-Asibu, W.W. Schultz and P.C. Wang, "Modelling and Analysis of Metal Transfer in Gas Metal Arc Welding,” J. Phys. D: Appl. Phys. 36, 2003, pp. 1143-1152.
[35] K.C. Tsao and C.S. Wu, "Fluid Flow and Heat Transfer in GMA Weld Pools", Weld. J., 1998, pp 70s-75s.

[36] S. Kumar and S.C. Bhaduri, "Three-Dimensional Finite Element Modeling of Gas Metal-Arc Welding," Metall. Trans. 25B, 1994, pp. 435-441.

[37] S.-D. Kim and S.-J. Na. "A Study on the Effect of Constant Tube-to-Workpiece Distance on Weld Pool Shape in Gas Metal Arc Welding," Welding J. 74(5), 1995, pp. 141-152s.

[38] C.-H. Kim, W. Zhang and T. DebRoy, "Modeling of Temperature Field and Solidified Surface Profile during Gas-Metal Arc Fillet Welding,” J. Appl. Phys. 94, 2003, pp. 2667-2679.

[39] S. Ohring and H.J. Lugt, "Numerical Simulation of a Time-Dependent 3-D GMA Weld Pool due to a Moving Arc” Welding J., 1999, pp. 416-424s

[40] Z. Cao, Z. Yang and X.L. Chen., "Three-Dimensional Simulation of Transient GMA Weld Poo with Free Surface," Welding J., 2004, pp. 169-176s.

[41] Y. Wang and H.L. Tsai, "Impingement of Filler Droplets and Weld Pool Dynamics during Gas Metal Arc Welding Process,” Int. J. Heat and Mass Transfer 44, 2001, pp. 2067-2080.

[42] Y. Wang, Q. Shi and H.L. Tsai, "Modeling of the Effects of Surface-Active Elements on Flow Patterns and Weld Penetration,” Metall. Trans. 32B, 2001, pp. 145-161.

[43] Y. Wang and H.L. Tsai, "Effects of Surface Active Elements on Weld Pool Fluid Flow and Weld Penetration in Gas Metal Arc Welding,” Metall. Trans. 32B, 2001, pp. 501-515.

[44] Diao, Q.Z. and Tsai, H.L., 1993, "Modeling of Solute Redistribution in the Mushy Zone during Solidification of Aluminum-Copper Alloys”, Metall. Trans., 24A, pp. 963-973.

[45] Torrey, M.D., Cloutman, L.D., Mjolsness, R.C., and Hirt, C.W., 1985, "NASA-VOF2D: A Computer Program for Incompressible Flows with Free Surfaces,” LA-10612-MS, Los Alamos National Laboratory.

[46] J. Hu, "Heat and Mass Transfer in the Gas Metal Arc Welding Process," Ph.D. Dissertation, 2005, University of Missouri-Rolla, Rolla, Missouri, USA.

[47] Patanka, S.V., 1980, "Numerical Heat Transfer and Fluid Flow”, New York: McGraw-Hill. 